Article

\title{
Oxidative Debromination and Degradation of Tetrabromo-bisphenol A by a Functionalized Silica-Supported Iron(III)-tetrakis( $p$-sulfonatophenyl)porphyrin Catalyst
}

\author{
Qianqian Zhu, Yusuke Mizutani, Shohei Maeno and Masami Fukushima * \\ Laboratory of Chemical Resources, Division of Sustainable Resources Engineering, \\ Graduate School of Engineering, Hokkaido University, Sapporo 060-8628, Japan \\ * Author to whom correspondence should be addressed; E-Mail: m-fukush@eng.hokudai.ac.jp; \\ Tel./Fax: +81-11-706-6304.
}

Received: 15 April 2013; in revised form: 7 May 2013 / Accepted: 7 May 2013 /

Published: 10 May 2013

\begin{abstract}
Tetrabromobisphenol A (TBBPA), a commonly used brominated flame retardant, also functions as an endocrine disruptor. Thus, the degradation of TBBPA has attracted considerable interest among the scientific community. Iron(III)-porphyrin complexes are generally regarded as "green" catalysts and have been reported to catalyze the efficient degradation and dehalogenation of halogenated phenols in environmental wastewaters. However, they are quickly deactivated due to self-degradation in the presence of an oxygen donor, such as $\mathrm{KHSO}_{5}$. In the present study, an iron(III)-tetrakis ( $p$-sulfonatophenyl)-porphyrin (FeTPPS) was immobilized on imidazole-modified silica (FeTPPS/IPS) via coordination of the Fe(III) with the nitrogen atom in imidazole to suppress self-degradation and thus enhance the catalyst reusability. The oxidative degradation and debromination of TBBPA and the influence of humic acid (HA), a major component in leachates, on the oxidation of TBBPA was investigated. More than $95 \%$ of the TBBPA was degraded in the $\mathrm{pH}$ range from 3 to 8 in the absence of $\mathrm{HA}$, while the optimal $\mathrm{pH}$ for the reaction was at $\mathrm{pH} 8$ in the presence of HA. Although the rate of degradation was decreased in the presence of HA, over 95\% of the TBBPA was degraded within $12 \mathrm{~h}$ in the presence of $28 \mathrm{mg}_{-} \mathrm{C} \mathrm{L}^{-1}$ of HA. At $\mathrm{pH} 8$, the FeTPPS/IPS catalyst could be reused up to 10 times without any detectable loss of activity for TBBPA for degradation and debromination, even in the presence of HA.
\end{abstract}


Keywords: iron(III)-porphyrin; humic acid; silica support; catalytic oxidation; tetrabromobisphenol A

\section{Introduction}

Tetrabromobisphenol A (TBBPA), a widely used brominated flame retardant (BFR), is used in the treatment of paper, textiles, plastics, electronic equipment, upholstered furniture and chiefly in epoxy resins that are used in circuit board laminates [1]. The leaching of BFRs, as well as TBBPA, from wastes derived from such materials in landfills is facilitated in the presence of humic acid (HA), which is a major component in landfill leachates [2,3]. Many studies have shown that TBBPA can induce cytotoxicity and hepatotoxicity, and it has the potential to disrupt estrogen signaling [4], therefore, the development of effective methods for removing TBBPA from landfill leachates is an important issue. Methods have been reported for oxidative degradation of TBBPA (e.g., birnessite oxidation [5], photooxidation [6] and permanganate oxidation [7]), but most involve the cleavage of the $\beta$-carbon in TBBPA, and not debromination. In addition, the influence of other contaminants, such as HAs, on TBBPA oxidation has not been investigated in detail, even though it is well known that HAs are major components of landfill leachates.

Considerable interest has developed regarding Fe-based biomimetic catalysts, such as iron-porphyrins, because of their ability to mimic cytochrome P450 enzymes that catalyze a variety of oxidation reactions [8,9]. Iron porphyrins can oxidize bromophenols in homogenous solutions [10,11], but these types of catalysts are deactivated due to rapid self-degradation under the highly oxidative conditions and by dimerization via the formation of $\mu$-oxo iron(III) species [12-14]. The immobilization of such catalysts on a suitable support has been used to increase their stability towards oxidative selfdegradation and to prevent catalyst deactivation caused by dimerization [15-22]. Among the supports used to immobilize metalloporphyrins, inorganic supports such as $\mathrm{SiO}_{2}$ are preferred, because of its low cost, availability, mechanical robustness and chemical inertness.

In a previous study, our research group examined the degradation of TBBPA using a homogeneous iron(III)-porphyrin catalytic system. The findings indicated that the oxidation was not efficient and no debromination was observed because the catalyst underwent self-degradation and inhibition by contaminating HA [10]. Although the immobilization of anionic iron(III)-porphyrins on an anion-exchange resin was examined, the catalytic activity for 2,6-dibromophenol oxidation decreased because of anion-exchange reactions between iron(III)-porphyrin and HA, 2,6-dibromophenol or oxidation products derived from it [23]. In addition, the positively charged surface of the anion-exchange resin can also adsorb anionic HA, which results in a decrease in degradation performance. However, nitrogen atoms that are included in the functional groups of the anionexchange resins can serve as a ligand for coordination with iron(III). If the iron(III) in the anionic porphyrin could be tightly attached to the nitrogen atom on the support by coordination, the surface potentials of the solid catalysts would be changed to negative after complexation. Using such a type of the solid catalyst, the adsorption of anionic concomitants, such as HAs, would be suppressed, thus producing a stabile form of iron(III)-porphyrin catalyst on the support. 
In the present study, an anionic iron(III)-tetrakis( $p$-sulfonatephenyl)porphyrin (FeTPPS) immobilized on silica modified with an imidazole was examined for use as a catalyst for the enhanced degradation and debromination of TBBPA in the presence of HA. In addition, the influence of HA on the rate of TBBPA degradation, debromination and reusability were investigated.

\section{Results and Discussion}

\subsection{Characterization of FeTPPS / IPS}

The amount of FeTPPS molecules bound to the surface of the 3-(1-imidazolyl)propylcarbamoyl-3'aminopropylsilica (IPS) was estimated by the change in absorbance at $394 \mathrm{~nm}$ of the Soret band in UV-visible absorption spectra. The relative absorption at a wavelength of $394 \mathrm{~nm}$ (corresponding to the Soret band of FeTPPS) between a stock solution of FeTPPS and the solution obtained after removing the FeTPPS/IPS was used to determine the concentration of FeTPPS molecules bound to the IPS. The findings indicated that $32.7 \mu \mathrm{mol}$ of FeTPPS was immobilized on $1 \mathrm{~g}$ of IPS.

FT-IR spectra of silica, IPS and FeTPPS/IPS are shown in Figure 1. The FT-IR spectrum of IPS contained characteristic vibration bands in the $2800-3000 \mathrm{~cm}^{-1}$ region, corresponding to symmetrical and asymmetrical C-H stretching vibrations. The absorbance in the $1400-1600 \mathrm{~cm}^{-1}$ region is assigned to $\mathrm{C}=\mathrm{C}, \mathrm{C}=\mathrm{N}$ ring stretching (skeletal bands) as well as the $\mathrm{C}=\mathrm{O}$ stretching vibration which was observed in the FT-IR spectra of IPS and FeTPPS/IPS.

Figure 1. FT-IR spectra of silica gel, IPS and FeTPPS / IPS with KBr pellet.

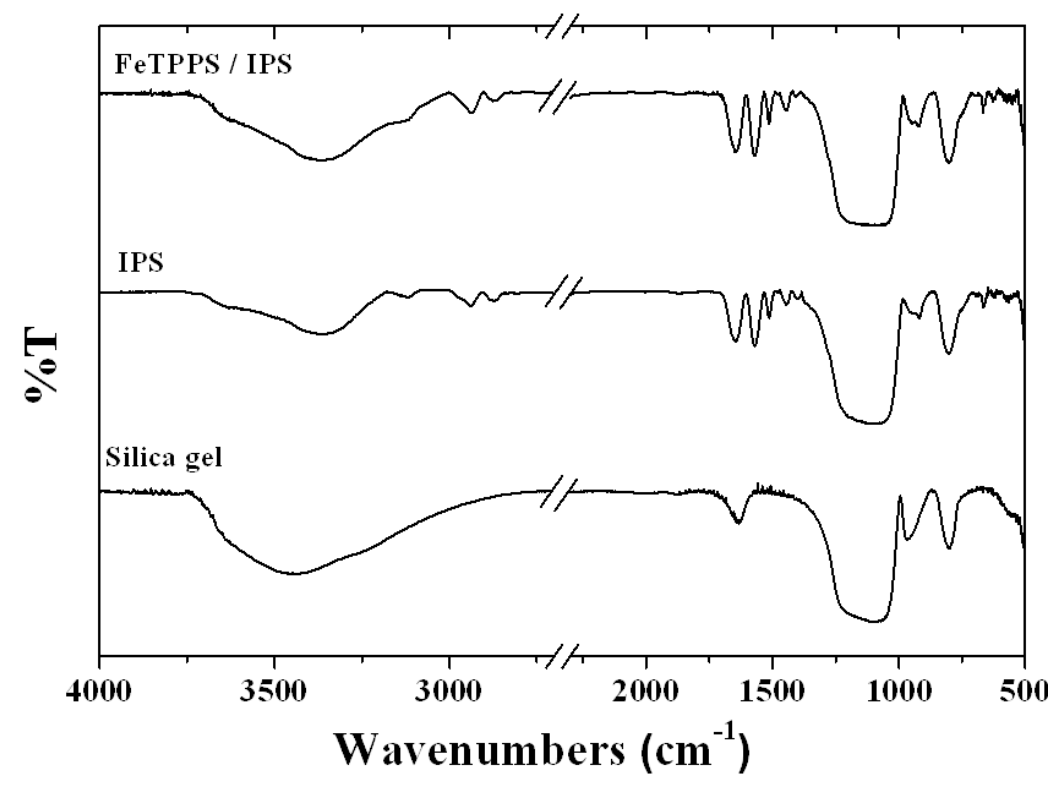

The change in the surface chemistry of the catalyst was characterized by zeta potential analysis, which is related to the surface charge (Figure 2). The unmodified silica had a negative zeta potential in the $\mathrm{pH}$ range of 3 to 9 , which reflected a large negative surface charge due to the presence of deprotonated silanol groups. The FeTPPS/IPS catalyst had a negative zeta potential at $\mathrm{pH}$ values above 7.1. The FeTPPS/IPS catalyst had a positive zeta potential below $\mathrm{pH} 7.1$, which can be attributed to the protonation of uncomplexed imidazole group in IPS. The zeta potential verse $\mathrm{pH}$ curve $(\bullet$ in Figure 2 ) 
for the reused catalyst was similar with fresh catalyst ( $\mathbf{n}$ in Figure 2). However, the magnitude of the zeta potential was increased in the $\mathrm{pH}$ range from 3 to 9, compared with the fresh catalyst. In addition, the point of zero charge (PZC) was shifted from $\mathrm{pH} 7.1$ to 7.5 as a result of recycling. This may be due to the release and degradation of some FeTPPS during the oxidation reaction.

Figure 2. The $\mathrm{pH}$ dependence on the Zeta potential for silica, FeTPPS/IPS and the FeTPPS/IPS that was reused 5 times.

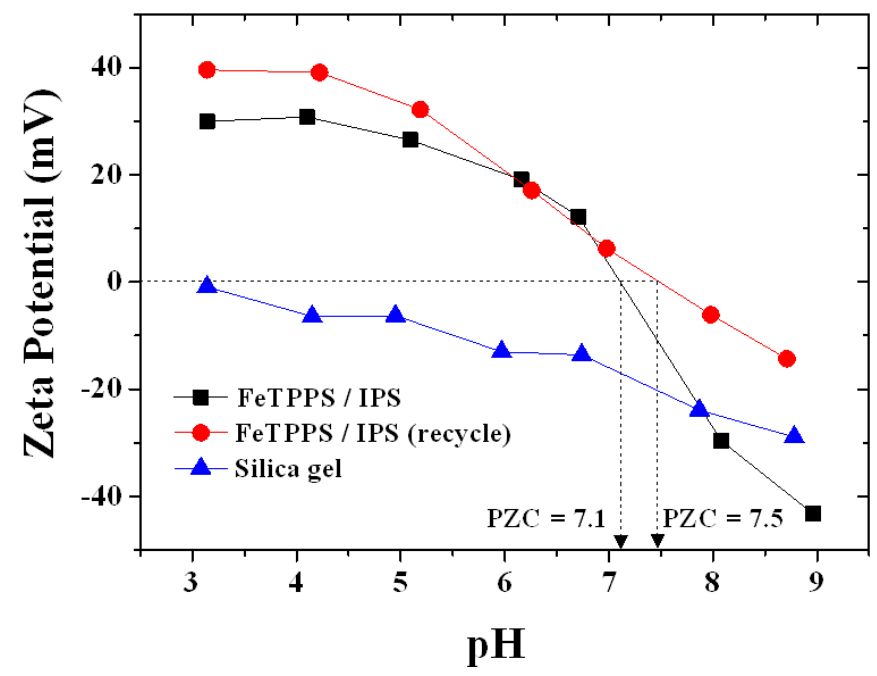

\subsection{Influence of $p H$ on the Degradation of TBBPA}

Since the $\mathrm{pH}$ was not only related to the redox potential of the oxidant but also to species distribution of TBBPA and other concomitants in aqueous solutions, the influence of $\mathrm{pH}$ on the degradation of TBBPA was investigated. In the absence of HA, the degradation of TBBPA was not dependent on the $\mathrm{pH}$ of the solution. However, in the presence of HA, the reaction was clearly $\mathrm{pH}$ dependent, and the presence of HA also affected the degradation reaction. As shown in Figure 3a, in the presence of HA, the percentage of degraded TBBPA increased with increasing $\mathrm{pH}$ and the highest degradation performance was observed at $\mathrm{pH} 8$, where more than 95\% the TBBPA was degraded in the presence of HA, indicating that the oxidative degradation of TBBPA is inhibited by HA. This inhibition was enhanced in the lower $\mathrm{pH}$ range and became weaker at higher $\mathrm{pH}$. The zeta potential of the FeTPPS/IPS indicated that the catalyst had negative surface charge at $\mathrm{pH}$ values above 7.1 and a positive surface charge at $\mathrm{pH}$ values below 7.1. Because HA has a large amount of negative surface charge [24], it can easily be adsorbed on the FeTPPS/IPS surface at a pH below 7.1. The interaction of TBBPA with catalytic sites could be blocked due to the adsorption of HA at a pH lower than 7 . The surface charge of the catalyst changed to negative at $\mathrm{pH}$ values higher than 7.1. In this $\mathrm{pH}$ range, the HA appears to be excluded from the catalyst surface by electrostatic repulsion. Therefore, the inhibition by $\mathrm{HA}$ became weaker in a high $\mathrm{pH}$ range. Debromination was observed during the oxidation reaction in the $\mathrm{pH}$ range from $\mathrm{pH} 4$ to 8 (Figure $3 \mathrm{~b}$ ). Although, in a previous study, no debromination was observed in the case of a homogeneous system [10], $\mathrm{Br}^{-}$was clearly detected in the reaction mixture in the FeTPPS/IPS catalytic system. The low $\mathrm{pH}$ condition was beneficial for debromination, especially in the absence of HA, and the highest debromination value was found at $\mathrm{pH} 4$. The highest rate of debromination was also observed at $\mathrm{pH} 4$ in the presence of HA. However, 
compared with HA free conditions, the extent of debromination decreased in the presence of HA due to the drastic decrease in the rate of degradation of TBBPA. At $\mathrm{pH} 6$ and 7, debromination was enhanced by HA, even the degradation of TBBPA was inhibited by HA. At $\mathrm{pH}$ 8, although the rate of debromination decreased slightly in the presence of HA, the percent TBBPA degradation was the highest in the $\mathrm{pH}$ range from 3 to 8 in the presence or absence of HA. In addition, the typical $\mathrm{pH}$ range for a leachate is reported to be 6.7-12 [2,3]. Therefore, the influence of HA and catalyst concentration on the degradation of TBBPA were examined at $\mathrm{pH} 8$.

Figure 3. (a) Influence of $\mathrm{pH}$ on percentage TBBPA degradation (b) Influence of $\mathrm{pH}$ on debromination. The reaction conditions were as follow: [TBBPA $]_{0}, 50 \mu \mathrm{M}$; [FeTPPS/IPS], $10 \mu \mathrm{M}\left(0.3 \mathrm{~g} \mathrm{~L}^{-1}\right)$; [KHSO 5 ], $1.0 \mathrm{mM}$; [HAs], $25 \mathrm{mg} \mathrm{L}^{-1}$; temperature, $25{ }^{\circ} \mathrm{C}$; reaction time, $4 \mathrm{~h}$.
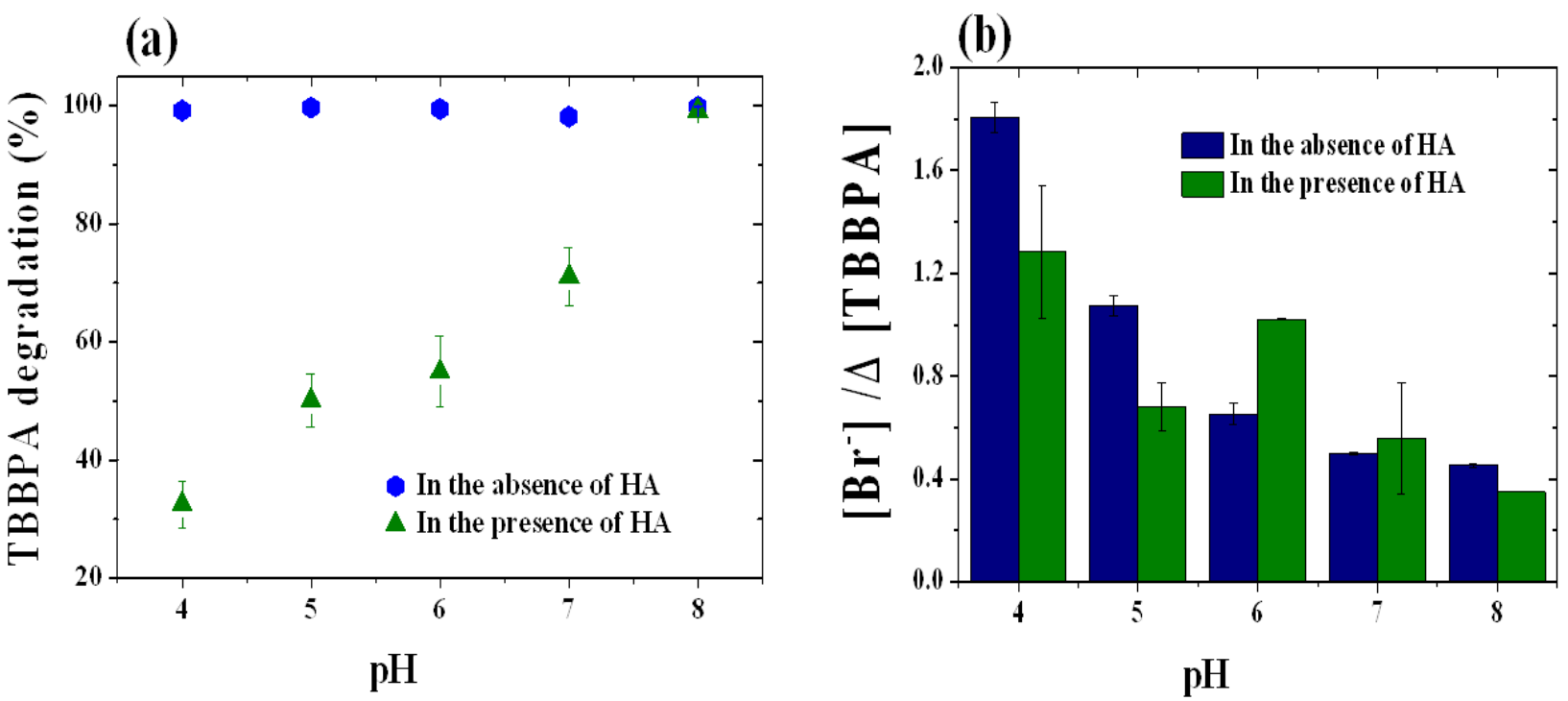

To identify the oxidation products produced in the reactions, $n$-hexane extracts of reaction mixtures were analyzed by GC/MS for the 1.5-h and 5-h reaction periods. Figure 4 shows one of the chromatograms for an $n$-hexane extract of reaction mixtures at $\mathrm{pH} 8$ in the presence of HA. For the $1.5 \mathrm{~h}$ reaction period, the peak at $17.8 \mathrm{~min}$ of retention time was detected as a major oxidation product (Figure 4a). This peak was assigned as 4-(2-hydroxyisopropyl)-2,6-dibromophenol (2HIP-2,6DBP) acetate from the mass spectrum: $\mathrm{m} / \mathrm{z}$ [relative intensity, fragment identify], $352\left[2.65, \mathrm{M}^{+}\right], 310[30.8$, $\left.\left(\mathrm{M}-\mathrm{CH}_{2} \mathrm{CO}\right)^{+}\right], 295\left[100,\left(\mathrm{M}-\mathrm{CH}_{3} \mathrm{CH}_{2} \mathrm{CO}\right)^{+}\right], 252$ [48.3, $\left.\mathrm{C}_{6} \mathrm{H}_{4} \mathrm{OBr}_{2}{ }^{+}\right]$. However, 2HIP-2,6DBP decreased for the $5 \mathrm{~h}$ reaction period, and the peak at $53.0 \mathrm{~min}$ of the retention time significantly increased (Figure 4b). This peak was assigned as the trimer of 2,6-dibromophenol and the mass spectral identification was as follows: $m / z$ [relative intensity, fragment identify], 836 [71.0, $\mathrm{M}^{+}$], 794 [100, $\left.\left(\mathrm{M}-\mathrm{CH}_{2} \mathrm{CO}\right)^{+}\right], 779$ [44.2, $\left.\left(\mathrm{M}-\mathrm{CH}_{3} \mathrm{CH}_{2} \mathrm{CO}\right)^{+}\right], 756$ [48.3, (M-Br $\left.)^{+}\right], 293\left[14.8, \mathrm{C}_{6} \mathrm{H}_{2}\left(\mathrm{CH}_{3} \mathrm{CO}_{2}\right) \mathrm{Br}_{2}{ }^{+}\right]$, $267\left[28.8, \mathrm{C}_{6} \mathrm{H}_{2} \mathrm{O}(\mathrm{OH}) \mathrm{Br}_{2}{ }^{+}\right]$. The retention time and mass spectrum of 2HIP-2,6DBP acetate in the reaction mixtures were in good agreement with those for the acetate of the standard sample. In previous reports of TBBPA oxidation [5,6], while 2HIP-2,6DBP was found as one of the main byproducts, 2,6-dibromo- $p$-benzoquinone (2,6DBQ) was also detected as a main byproduct. However, no 2,6DBQ was found in the homogeneous FeTPPS-KHSO ${ }_{5}$ catalytic system [10], even at pH 4 and 6 
as well as at $\mathrm{pH} 8$ for any of the reaction periods. The patterns of oxidation products were also not varied by solution $\mathrm{pH}$ (for at $\mathrm{pH} 4$ and 6) for the heterogeneous FeTPPS/IPS-KHSO 5 catalytic system.

Figure 4. GC/MS chromatograms of $n$-hexane extract from the reaction mixture at $\mathrm{pH} 8$ in the presence of HA. Reaction period (a) $1.5 \mathrm{~h}$, (b) $5 \mathrm{~h}$. Reaction conditions: [TBBPA] $]_{0}, 50 \mu \mathrm{M}$; [FeTPPS/IPS], $10 \mu \mathrm{M}\left(0.3 \mathrm{~g} \mathrm{~L}^{-1}\right)$; [KHSO 5 ], $1.0 \mathrm{mM}$; [HAs], $25 \mathrm{mg} \mathrm{L}^{-1}$, temperature $25{ }^{\circ} \mathrm{C}$.

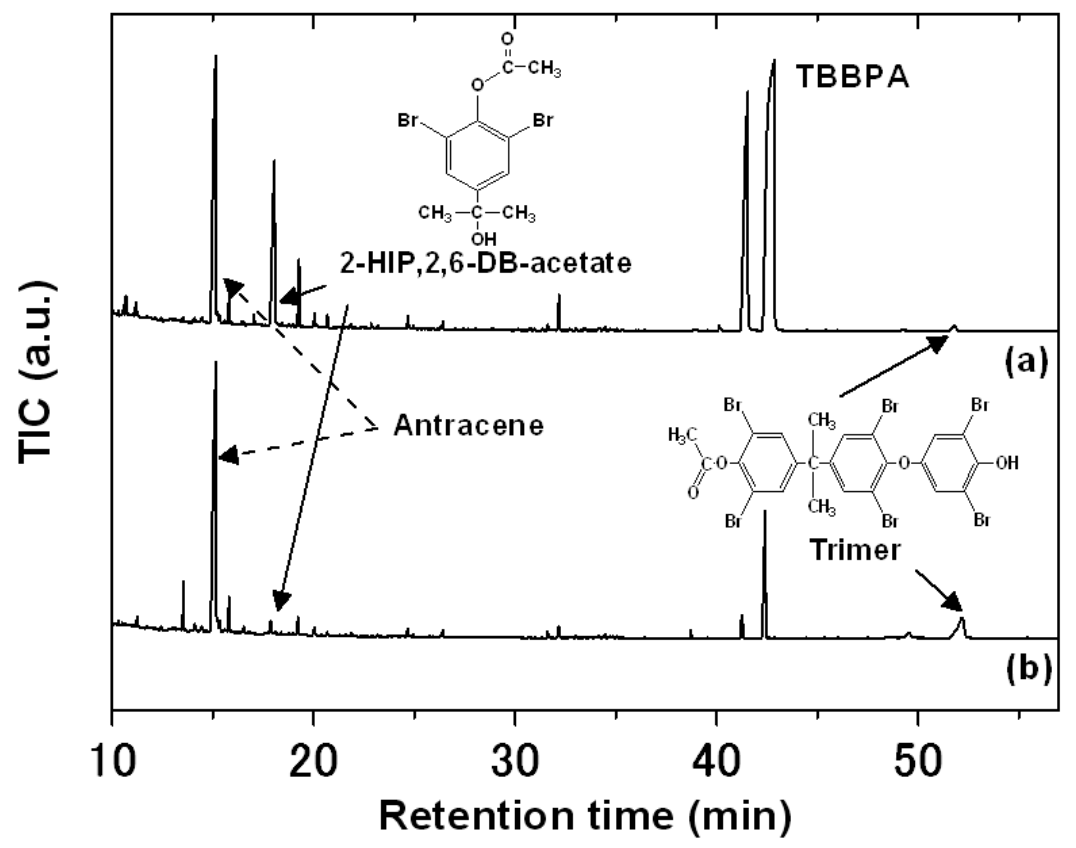

\subsection{Influence of Catalyst Concentration on the TBBPA Degradation and Debromination}

Figure 5 shows the influence of catalyst concentration on the degradation of and debromination of TBBPA, in which the $\triangle[$ TBBPA] represents the concentration of degraded TBBPA. A $0.7-3.4 \%$ decrease in the concentration of TBBPA was found in the presence of the FeTPPS/IPS $(10-34 \mu \mathrm{M})$ without $\mathrm{KHSO}_{5}$. These results suggest that the contribution of TBBPA adsorption to the solid catalyst is minor in the case of $\Delta[$ TBBPA]. The $\Delta[$ TBBPA] steeply increased up to a concentration of $3.5 \mu \mathrm{M}$ of the FeTPPS/IPS catalyst, and then gradually increased at concentrations up to $34 \mu \mathrm{M}$ (Figure $5 \mathrm{a}$ ). In the absence of the solid catalyst, a small amount of TBBPA degradation $(3 \mu \mathrm{M})$ and $\mathrm{Br}^{-}$release $(4 \mu \mathrm{M})$ was observed for a $35 \mathrm{~min}$ reaction period. For the debromination (Figure $5 \mathrm{~b}$ ), the concentration of the released $\mathrm{Br}^{-}$reached a plateau of $3.5-17 \mu \mathrm{M}$ of the FeTPPS/IPS catalyst, but decreased at $34 \mu \mathrm{M}$. These results indicate that the presence of the catalyst enhances the degradation of TBBPA. The decrease in debromination at a FeTPPS/IPS concentration of $34 \mu \mathrm{M}$ may be due to the enhanced oxidation of $\mathrm{Br}^{-}$ at higher catalyst concentrations. The turn over number for TBBPA degradation and debromination, as estimated for $3.5 \mu \mathrm{M}$ of the FeTPPS/IPS catalyst, was $7.3 \pm 0.3$ and $5.1 \pm 0.1$, respectively. 
Figure 5. Influence of FeTPPS/IPS concentration on the (a) degradation and (b) debromination of TBBPA. [TBBPA $]_{0}, 50 \mu \mathrm{M} ; \mathrm{pH}=8$; [KHSO 5 ], $1 \mathrm{mM}$; temperature, $25{ }^{\circ} \mathrm{C}$; reaction time, $35 \mathrm{~min}$. The FeTPPS/IPS concentration at $0.3 \mathrm{~g} \mathrm{~L}^{-1}$ corresponds to $10 \mu \mathrm{M}$.
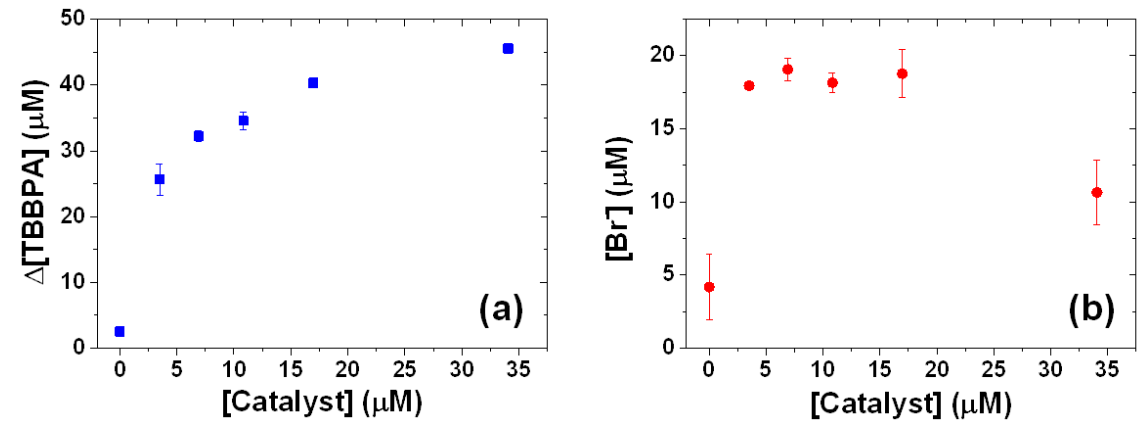

\subsection{Influence of HA Concentration}

HA is present at levels of 20-200 mg-C L $\mathrm{L}^{-1}$ levels in landfill leachates [3], and HA can affect the distribution and oxidation reactions of organic pollutants. The influence of HA concentration was examined to assess the practical use of the FeTPPS/IPS catalyst. The pseudo-first-order rate constant $\left(k_{\mathrm{obs}}\right)$ of TBBPA decreased with increasing concentration of HA. When the HA concentration increased from 2.8 to $14 \mathrm{mg}-\mathrm{C} \mathrm{L}^{-1}$, the $k_{\text {obs }}$ dramatically decreased from 1.6 to $0.3 \mathrm{~h}^{-1}$. With a further increase in the concentration of HA, the $k_{\text {obs }}$ decreased further. From the insert in Figure 6, a drop-off in the initial degradation rate was observed with a small $\left(2.8 \mathrm{mg}_{-} \mathrm{C} \mathrm{L}^{-1}\right)$ mount of HA. However, when the reaction time was prolonged, the percent degradation TBBPA rapidly reached values higher than 95\% within $5 \mathrm{~h}$ in the case of an HA concentration lower than $14 \mathrm{mg}-\mathrm{C} \mathrm{L}^{-1}$. Over $95 \%$ the TBBPA was degraded within $9 \mathrm{~h}$ for HA concentrations of up to $29 \mathrm{mg}-\mathrm{C} \mathrm{L}^{-1}$. Even in the presence of high concentrations of HA, 58-87 mg-C L ${ }^{-1}$, over $75 \%$ of the TBBPA was degraded within $12 \mathrm{~h}$.

Figure 6. Influence of HA concentration on the pseudo-first-order rate constant $\left(k_{\mathrm{obs}}\right)$ for TBBPA degradation and variations in the percent TBBPA degradation (insertion). The reaction conditions were as follow: [TBBPA] $]_{0}, 50 \mu \mathrm{M}$; [FeTPPS/IPS], $10 \mu \mathrm{M}\left(0.3 \mathrm{~g} \mathrm{~L}^{-1}\right)$; [KHSO 5$], 1.0 \mathrm{mM} ; \mathrm{pH}=8$; temperature, $25^{\circ} \mathrm{C}$.

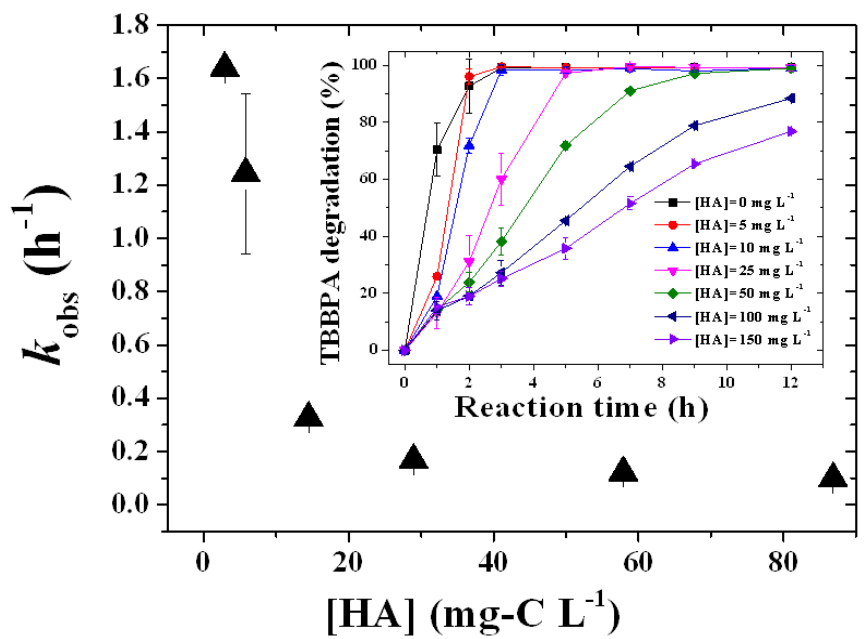




\subsection{Reusability of FeTPPS/IPS}

In terms of using FeTPPS/IPS for water treatment, catalyst reusability is an important factor from the economical point of view. After each reaction, the catalyst was isolated on a filter, and then washed with deionized water and acetone. The catalyst had a high degree of durability as demonstrated by the recyclability test shown in Figure 7 a. Over $95 \%$ of the TBBPA was degraded in the presence or absence of HA after five recyclings and more than $85 \%$ of the TBBPA was degraded after ten recyclings.

The reused catalyst exhibited a good catalytic activity up to ten catalytic runs with only a small loss in degradation efficiency. The debromination was around $0.4\left(\left[\mathrm{Br}^{-}\right] / \Delta[\mathrm{TBBPA}]\right)$ during the recyclability test (Figure 7b). However, the zeta potential of the FeTPPS/IPS increased slightly after five recyclings, as shown in Figure 2. At $\mathrm{pH} 8$, the zeta potential of the reused catalyst was $-6 \mathrm{mV}$ and the fresh catalyst was $-30 \mathrm{mV}$, indicating that the negative surface charge of the catalyst had decreased after the recyclability test. The HA would be predicted to be easily absorbed on the reused catalyst surface due to the change in surface charge, which would have an adverse impact on the degradation of TBBPA in the presence of HA. Therefore, with increasing catalyst reuse, the inhibition by HA became a larger issue (Figure 7a). The surface area of the reused catalyst $\left(194 \pm 10 \mathrm{~m}^{2} \mathrm{~g}^{-1}\right)$ was similar to that for the fresh catalyst $\left(215 \pm 6 \mathrm{~m}^{2} \mathrm{~g}^{-1}\right)$. In addition, Figure 8 shows Diffuse Reflectance UV-vis spectra for the fresh catalyst and after being used for five cycles. The fresh catalyst showed two peaks at $409 \mathrm{~nm}$ and $550 \mathrm{~nm}$. After five recyclings, all of the peaks remained, indicating that the structure of the FeTPPS remained intact during the oxidative degradation reaction. These results show that the higher catalytic activity of FeTPPS/IPS catalyst was retained after several recyclings.

Figure 7. Reusability of the catalyst (a) TBBPA degradation, (b) number of bromide ions released. The reaction conditions were as follow: [TBBPA] $]_{0}, 50 \mu \mathrm{M}$; [FeTPPS / IPS], $10 \mu \mathrm{M}\left(0.3 \mathrm{~g} \mathrm{~L}^{-1}\right)$; [KHSO 5 ], $1.0 \mathrm{mM}$; [HAs], $25 \mathrm{mg} \mathrm{L}^{-1}$; temperature, $25^{\circ} \mathrm{C} ; \mathrm{pH}=8$; reaction time, $4 \mathrm{~h}$ (in the absence of $\mathrm{HA}$ ), $20 \mathrm{~h}$ (in the presence of $\mathrm{HA}$ ).

(a)

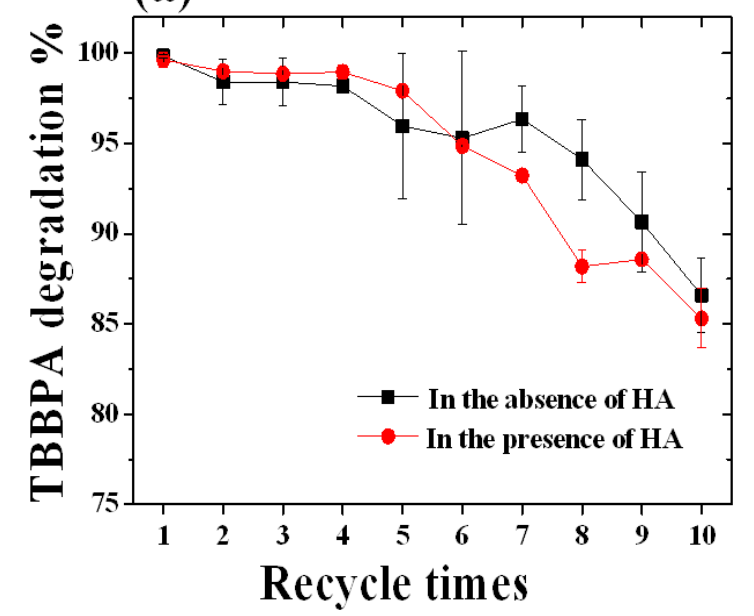

(b)

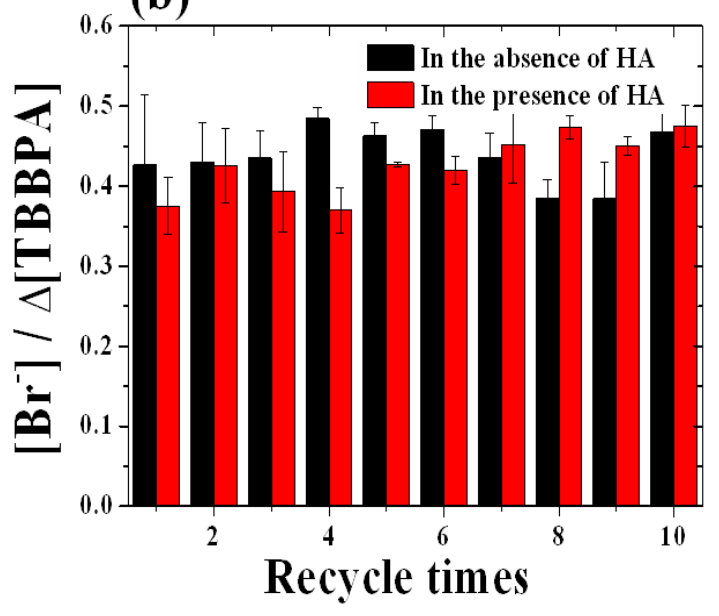


Figure 8. Diffuse reflectance UV-vis spectra for the FeTPPS/IPS catalyst before and after five recyclings.

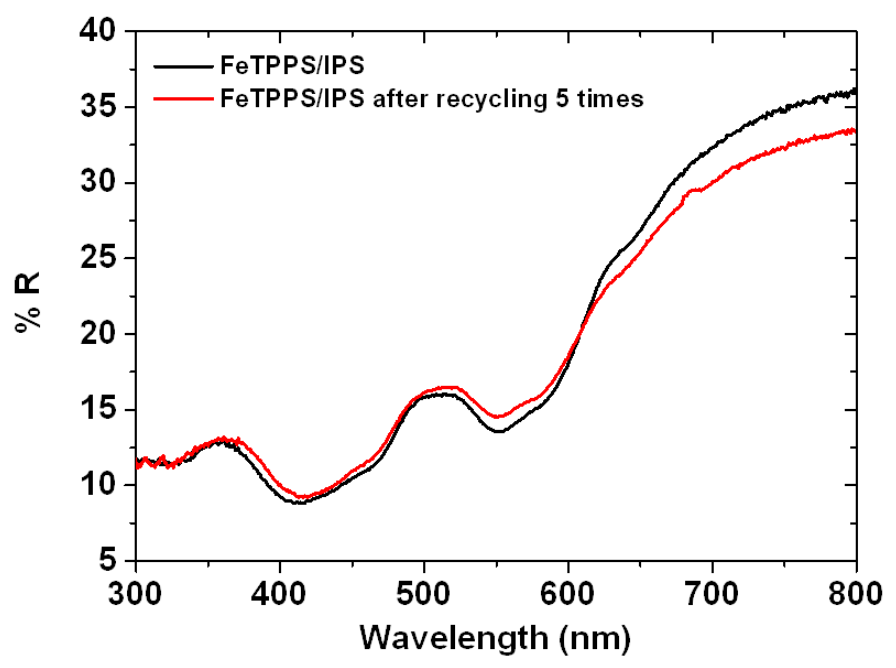

\section{Experimental}

\subsection{Materials}

The soil humic acid (SHA) sample used in this study was extracted from Shinshinotsu peat soil, as described in a previous report [25]. Tetrabromobisphenol A (TBBPA), 3-isocyanatopropyltrimethoxysilane and $N$-(3-aminopropyl)imidazole, were purchased from Tokyo Chemical Industry (Tokyo, Japan). FeTPPS was synthesized according to the reported procedure [26]. $\mathrm{KHSO}_{5}$ was obtained as a triple salt, $2 \mathrm{KHSO}_{5} \cdot \mathrm{KHSO}_{4} \cdot \mathrm{K}_{2} \mathrm{SO}_{4}$ (Merck, Darmstadt, Germany).

\subsection{Synthesis of Silica Supported FeTPPS Catalyst}

Scheme 1 shows the strategy used in the synthesis of the catalyst. The silica gel supported $\mathrm{Fe}(\mathrm{III}) \mathrm{TPPS}$ catalyst was synthesized by a previously reported method [18], with minor modifications. In a 2-neck flask, (3-isocyanatopropyl)triethoxysilane $(1.3 \mathrm{~mL})$ and $N$-(3-aminopropyl) imidazole $(700 \mu \mathrm{L})$ were added to dioxane $(20 \mathrm{~mL})$ to synthesize 3-(1-imidazolyl)propylcarbamoyl-3'-aminopropyltriethoxysilane. The mixture was stirred for $12 \mathrm{~h}$ at $70^{\circ} \mathrm{C}$. Subsequently, $1.5 \mathrm{~g}$ of silica gel (10-40 mesh, Wako Pure Chemicals, Osaka, Japan) was added, and the mixture was stirred at $80{ }^{\circ} \mathrm{C}$ for $12 \mathrm{~h}$. The resulting solid was collected on a filter and consecutively washed with $0.5 \mathrm{M} \mathrm{HCl}, \mathrm{H}_{2} \mathrm{O}, 0.1 \mathrm{M} \mathrm{NaOH}$ and finally washed with $\mathrm{H}_{2} \mathrm{O}$. The 3-(1-imidazolyl)propylcarbamoyl-3'-aminopropylsilica (IPS) was then carefully dried overnight in vacuum oven at $50{ }^{\circ} \mathrm{C}$. In a $100 \mathrm{~mL}$ flask, IPS $(0.5 \mathrm{~g})$ was added to FeTPPS solution $(3.0 \mathrm{mM}, 15 \mathrm{~mL})$. The mixture was shaken at $25^{\circ} \mathrm{C}, 150 \mathrm{rpm}$ under $24 \mathrm{~h}$ in the dark. After the reaction, the FeTPPS/IPS was collected and washed with $1 \mathrm{M} \mathrm{NaCl}$ solution, ultra-pure water, and dried under vacuum. 
Scheme 1. The synthesis of IPS and FeTPPS/IPS.

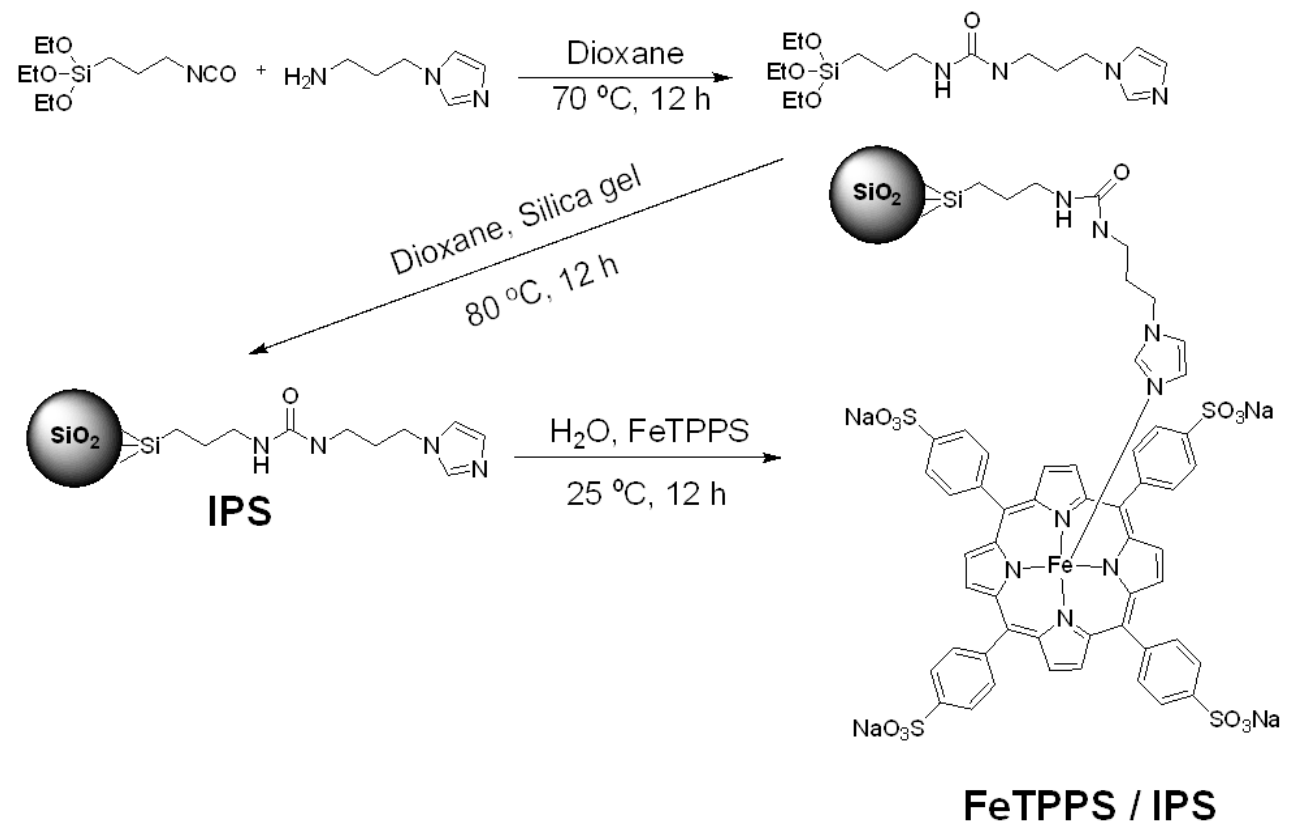

\subsection{Characterization of the Synthesized Catalyst}

The catalyst loading amount was estimated using UV-visible absorption spectroscopy. UV-visible absorption spectroscopy and Diffuse Reflectance UV-vis spectra were obtained using a V-630 type spectrophotometer (Japan Spectroscopic Co. Ltd., Japan). FT-IR spectra were recorded using an FT/IR 600 type spectrometer (Japan Spectroscopic Co. Ltd.) with $\mathrm{KBr}$ pellets. The specific surface areas of the samples were obtained from $\mathrm{N}_{2}$ sorption isotherm at $77 \mathrm{~K}$ using a Beckman Coulter SA3100 (Brea, CA, USA). Zeta potentials were recorded using a Zetasizer Nano ZS90 (Malvern Instruments Ltd., Worcestershire, UK).

\subsection{Assay for TBBPA Degradation}

A $10 \mathrm{~mL}$ aliquot of a $0.02 \mathrm{M}$ citrate/phosphate buffer at $\mathrm{pH} 4-8$ was placed in a $100-\mathrm{mL}$ Erlenmeyer flask. An aliquot $(50 \mu \mathrm{L})$ of $0.01 \mathrm{M}$ TBBPA in acetonitrile and the FeTPPS/IPS ( $3 \mathrm{mg}$ ) was then added to the buffer. Subsequently, aqueous solutions of $1,000 \mathrm{mg} \mathrm{L}^{-1} \mathrm{HA}$ in $0.05 \mathrm{M} \mathrm{NaOH}$ solution and $0.1 \mathrm{M}$ aqueous potassium monopersulfate (KHSO5, $100 \mu \mathrm{L}$ ) were added, and the flask was then allowed to shake at $25{ }^{\circ} \mathrm{C}$ in an incubator. After the reaction, the concentrations of the remained TBBPA were measured by an HPLC with a UV detector. The separation of TBBPA in the reaction mixture was accomplished with a COSMOSIL $5 \mathrm{C}_{18}$-AR-II column $(4.6 \mathrm{~mm} \varnothing \times 250 \mathrm{~mm})$. The mobile phase consisted of a mixture of methanol and $0.08 \%$ of $\mathrm{H}_{3} \mathrm{PO}_{4}$ aqueous $(78 / 22$, v/v). The flow rate of the eluent and the detection wavelength were set to $1.0 \mathrm{~mL} \mathrm{~min}^{-1}$ and at $220 \mathrm{~nm}$, respectively. The released $\mathrm{Br}^{-}$was analyzed by ion chromatography (ICS-90 type, Dionex). The mobile phase was an aqueous mixture of $2.7 \mathrm{mM} \mathrm{Na}_{2} \mathrm{CO}_{3}$ and $0.3 \mathrm{mM} \mathrm{NaHCO}_{3}$, and the flow rate of the eluent was set at $1.5 \mathrm{~mL} \mathrm{~min}{ }^{-1}$. The degradation percent of TBBPA was calculated by the following equation: 


$$
\text { TBBPA degradation }(\%)=\frac{[\mathrm{TBBPA}]_{0}-[\mathrm{TBBPA}]_{t}}{[\mathrm{TBBPA}]_{0}} \times 100
$$

where $[\mathrm{TBBPA}]_{0}$ and $[\mathrm{TBBPA}]_{t}$ represent the TBBPA concentrations remained in the reaction mixture before and after a $t$-h reaction period, respectively. The pseudo first-order reaction rate constant, $k_{\mathrm{obs}}$ $\left(\mathrm{h}^{-1}\right)$, was estimated by non-linear least square regression analysis of the dataset for reaction time $(\mathrm{h})$ and $[\mathrm{TBBPA}]_{t} /[\mathrm{TBBPA}]_{0}$ to below equation:

$$
\frac{[\mathrm{TBBPA}]_{t}}{[\mathrm{TBBPA}]_{0}}=\exp \left(-k_{\mathrm{obs}} t\right)
$$

The turnover number for TBBPA degradation and debromination was calculated by dividing the concentration of degraded TBBPA $\left(\Delta[\mathrm{TBBPA}]=[\mathrm{TBBPA}]_{0}-[\mathrm{TBBPA}]_{t}\right)$ or released $\mathrm{Br}^{-}$by the catalyst concentration.

For the analysis of oxidation products, $1 \mathrm{M}$ aqueous ascorbic acid $(1 \mathrm{~mL})$ was added, and $\mathrm{pH}$ of the solution was adjusted to $11-11.5$ by adding aqueous $\mathrm{K}_{2} \mathrm{CO}_{3}\left(600 \mathrm{~g} \mathrm{~L}^{-1}\right)$. Subsequently, acetic anhydride $(5 \mathrm{~mL})$ was added dropwise to the solution, and a $1 \mathrm{mM}$ anthracene solution in hexane $(0.5 \mathrm{~mL})$ was added as an internal standard (ISTD) for the GC/MS analysis. This mixture was doubly extracted with $n$-hexane $(10 \mathrm{~mL})$, and the extract was then dried over anhydrous $\mathrm{Na}_{2} \mathrm{SO}_{4}$. After filtration, the extract was evaporated under a stream of dry $\mathrm{N}_{2}$, and the residue was dissolved in $n$-hexane $(0.25 \mathrm{~mL})$. An aliquot of the extract $(1 \mu \mathrm{L})$ was introduced into a GC-17A/QP5050 GC/MS system (Shimadzu, Kyoto, Japan). A Quadrex methyl silicon capillary column $(0.25 \mathrm{~mm}$ id $\times 25 \mathrm{~m})$ was employed in the separation. The temperature ramp was as follows: $65{ }^{\circ} \mathrm{C}$ for $1.5 \mathrm{~min}, 65-120{ }^{\circ} \mathrm{C}$ at $35{ }^{\circ} \mathrm{C} \mathrm{min}{ }^{-1}$, 120-300 ${ }^{\circ} \mathrm{C}$ at $4^{\circ} \mathrm{C} \min ^{-1}$ and a $300{ }^{\circ} \mathrm{C}$ held for $10 \mathrm{~min}$.

\section{Conclusions}

A FeTPPS/IPS catalyst was synthesized and its use in the degradation and debromination of TBBPA in the absence and presence of HA, a major component of leachates, was examined. This catalytic system was $\mathrm{pH}$ independent in the absence of $\mathrm{HA}$ and the highest catalytic activity was found to be at $\mathrm{pH} 8$ in the presence of HA. Although the presence of HA retarded the degradation of TBBPA, over $95 \%$ of the TBBPA was degraded in the case of HA $28 \mathrm{mg}_{-} \mathrm{C} \mathrm{L}^{-1}$. In addition, FeTPPS/IPS exhibited good catalytic activity for up to ten recyclings. As a green and efficient catalyst, FeTPPS/IPS has promise for use in the field of pollution control.

\section{Acknowledgments}

This work was supported by Grants-in-Aid for Scientific Research from the Japan Society for the Promotion of Science (21310048).

\section{Conflict of Interest}

The authors declare no conflict of interest. 


\section{References}

1. World Health Organization (WHO). Tetrabromobisphenol A and Derivatives: A General Introduction, Environmental Health Criteria 172; World Health Organization: Geneva, Switzerland, 1997.

2. Choi, K.-I.; Lee, S.-H.; Osako, M. Leaching of brominated flame retardants from TV housing plastics in the presence of dissolved humic matter. Chemosphere 2009, 74, 460-466.

3. Osako, M.; Kim, Y.-J.; Sakai, S. Leaching of brominated flame retardants in leachate from landfills in Japan. Chemosphere 2004, 57, 1571-1579.

4. Strack, S.; Detzel, T.; Wahl, M.; Kuch, B.; Krug, H.F. Cytotoxicity of TBBPA and effects on proliferation, cell cycle and MAPK pathways in mammalian cells. Chemosphere 2007, 67, S405-S411.

5. Lin, K.; Liu, W.; Gan, J. Reaction of tetrabromobisphenol A (TBBPA) with manganese dioxide: Kinetics, products, and pathways. Environ. Sci. Technol. 2009, 43, 4480-4486.

6. Han, S.-K.; Bilski, P.; Karriker, B.; Sik, R.H.; Chignell, C.F. Oxidation of flame retardant tetrabromobisphenol A by singlet oxygen. Environ. Sci. Technol. 2008, 42, 166-172.

7. Bastos, P.M.; Eriksson, J.; Green, N.; Bergman, A. A standardized method for assessment of oxidative transformations of brominated phenols in water. Chemosphere 2008, 70, 1196-1202.

8. Zhou, X.; Ji, H.; Huang, X. Photocatalytic degradation of methyl orange over metalloporphyrins supported on $\mathrm{TiO}_{2}$ degussa P25. Molecules 2012, 17, 1149-1158.

9. Sun, Z.-C.; She, Y.-B.; Zhou, Y.; Song, X.-F.; Li, K. Synthesis characterization and spectral properties of substituted tetraphenyl-porphyrin iron chloride complexes. Molecules 2011, 16, 2960-2970.

10. Fukushima, M.; Ishida, Y.; Shigematsu, S.; Kuramitz, H.; Nagao, S. Pattern of oxidation products derived from tetrabromobisphenol $\mathrm{A}$ in a catalytic system comprised of iron(III)-tetrakis ( $p$-sulfophenyl)porphyrin, $\mathrm{KHSO}_{5}$ and humic acids. Chemosphere 2010, 80, 860-865.

11. Fukushima, M.; Mizutani, Y.; Maeno, S.; Zhu, Q.; Kuramitz, H.; Nagao, S. Influence of halogen substituents on the catalytic oxidation of 2,4,6-halogenated phenols by $\mathrm{Fe}$ (III)-tetrakis ( $p$-hydroxyphenyl)porphyrins and potassium monopersulfate. Molecules 2012, 17, 48-60.

12. Nappa, M.J.; Tolman, C.A. Steric and electronic control of iron porphyrin catalyzed hydrocarbon oxidations. Inorg. Chem. 1985, 24, 4711-4719.

13. Fukushima, M.; Tatsumi, K. Effect of hydroxypropyl- $\beta$-cyclodextrin on the degradation of pentachlorophenol by potassium monopersulfate catalyzed with iron(III)-porphyrin complex. Environ. Sci. Technol. 2005, 39, 9337-9342.

14. Fukushima, M.; Tatsumi, K. Complex formation of water-soluble iron(III)-porphyrin with humic acids and their effects on the catalytic oxidation of pentachlorophenol. J. Mol. Catal. A-Chem. 2006, 245, 178-184.

15. Machado, G.S.; Castro, K.A.D.F.; Wypych, F.; Nakagaki, S. Immobilization of metalloporphyrins into nanotubes of natural halloysite toward selective catalysts for oxidation reactions. J. Mol. Catal. A-Chem. 2008, 283, 99-107.

16. Liu, J.; Guan, J.; Lu, M.; Kan, Q.; Li, Z. Hemoglobin immobilized with modified "fish-in-net" approach for the catalytic removal of aniline. J. Hazard. Mater. 2012, 217-218, 156-163. 
17. Nazari, K.; Shokrollahzadeh, S.; Mahmoudi, A.; Mesbahi, F.; Matin, N. S.; Moosavi-Movahedi, A.A. Iron(III)-protoporphyrin/MCM41 catalyst as a peroxidase enzyme model: Preparation and typical test reactions. J. Mol. Catal. A-Chem. 2005, 239, 1-9.

18. Nur, H.; Hamid, H.; Endud, S.; Hamdan, H.; Ramli, Z. Iron-porphyrin encapsulated in poly(methacrylic acid) and mesoporpous Al-MCM-41 as catalysts in the oxidation of benzene to phenol. Mater. Chem. Phys. 2006, 96, 337-342.

19. Zucca, P.; Mocci, G.; Rescigno, A.; Sanjust, E. 5,10,15,20-Tetrakis(4-sulfonato-phenyl)porphine$\mathrm{Mn}$ (III) immobilized on imidazole-activated silica as a novel lignin-peroxidase-like biomimetic catalyst. J. Mol. Cata. A-Chem. 2007, 278, 220-227.

20. Zucca, P.; Sollai, F.; Garau, A.; Rescigno, A.; Sanjust, E. Fe(III)-5,10,15,20-tetrakis(pentafluorophenyl)porphine supported on pyridyl-functionalized, crosslinked poly(vinyl alcohol) as a biomimetic versatile-peroxidase-like catalyst. J. Mol. Catal. A-Chem. 2009, 306, 89-96.

21. Christoforidis, K.C.; Serestatidou, E.; Louloudi, M.; Konstantinou, I.K.; Milaeva, E.R.; Deligiannakis, Y. Mechanism of catalytic degradation of 2,4,6-trichlorophenol by a Fe-porphyrin catalyst. Appl. Catal. B-Environ. 2011, 101, 417-424.

22. Christoforidis, K.C.; Louloudi, M.; Deligiannakis, Y. Complete dechlorination of pentachlorophenol by a heterogeneous $\mathrm{SiO} 2-\mathrm{Fe}-$ porphyrin catalyst. Appl. Catal. B-Environ. 2010, 95, 297-302.

23. Shigematsu, S.; Fukushima, M.; Nagao, S. Oxidative degradation of 2,6-dibromophenol using an anion-exchange resin supported supramolecular catalysts of iron(III)-5,10,15,20-tetrakis ( $p$-hydroxyphenyl)porphyrin bound to humic acid prepared via formaldehyde and ureaformaldehyde polycondensation. J. Environ. Sci. Heal. A 2010, 45, 1536-1542.

24. Fukushima, M.; Tanaka, S.; Hasebe, K.; Taga, M.; Nakamura, H. Interpretation of acid-base equilibrium of humic acid by continuous $\mathrm{p} K$ distribution model and electrostatic model. Anal. Chim. Acta 1995, 302, 365-373.

25. Fukushima, M.; Tanabe, Y.; Morimoto, K.; Tatsumi, K. Role of humic acid fraction with higher aromaticity in enhancing the activity of a biomimetic catalyst, tetra( $p$-sulfonatophenyl)porphineiron(III). Biomacromolecules 2007, 8, 386-391.

26. Kawasaki, M.; Kuriss, A.; Fukushima, M.; Sawada, A.; Tatsumi, K. Effects of pH and organic co-solvents on the oxidation of naphthalene with peroxosulfate catalyzed by iron(III) tetrakis (p-sulfonatophenyl)porphyrin, J. Porphyr. Phthalocya. 2003, 7, 645-650.

Sample Availability: Samples of the compounds are available from the authors.

(C) 2013 by the authors; licensee MDPI, Basel, Switzerland. This article is an open access article distributed under the terms and conditions of the Creative Commons Attribution license (http://creativecommons.org/licenses/by/3.0/). 